Some farmers resist increasing. incentive pay levels when compensating seasonal crew workers. They have hypothesized that workers have a certain earnings goal for each day and that once this goal is achieved, workers will go home. This study conducted in the San Joaquin Valley shows that crew workers generally do not have such an earnings goal. When piece-rate paid crew workers do leave work early, it is more likely because they are overly hot or tired or that wages are low.

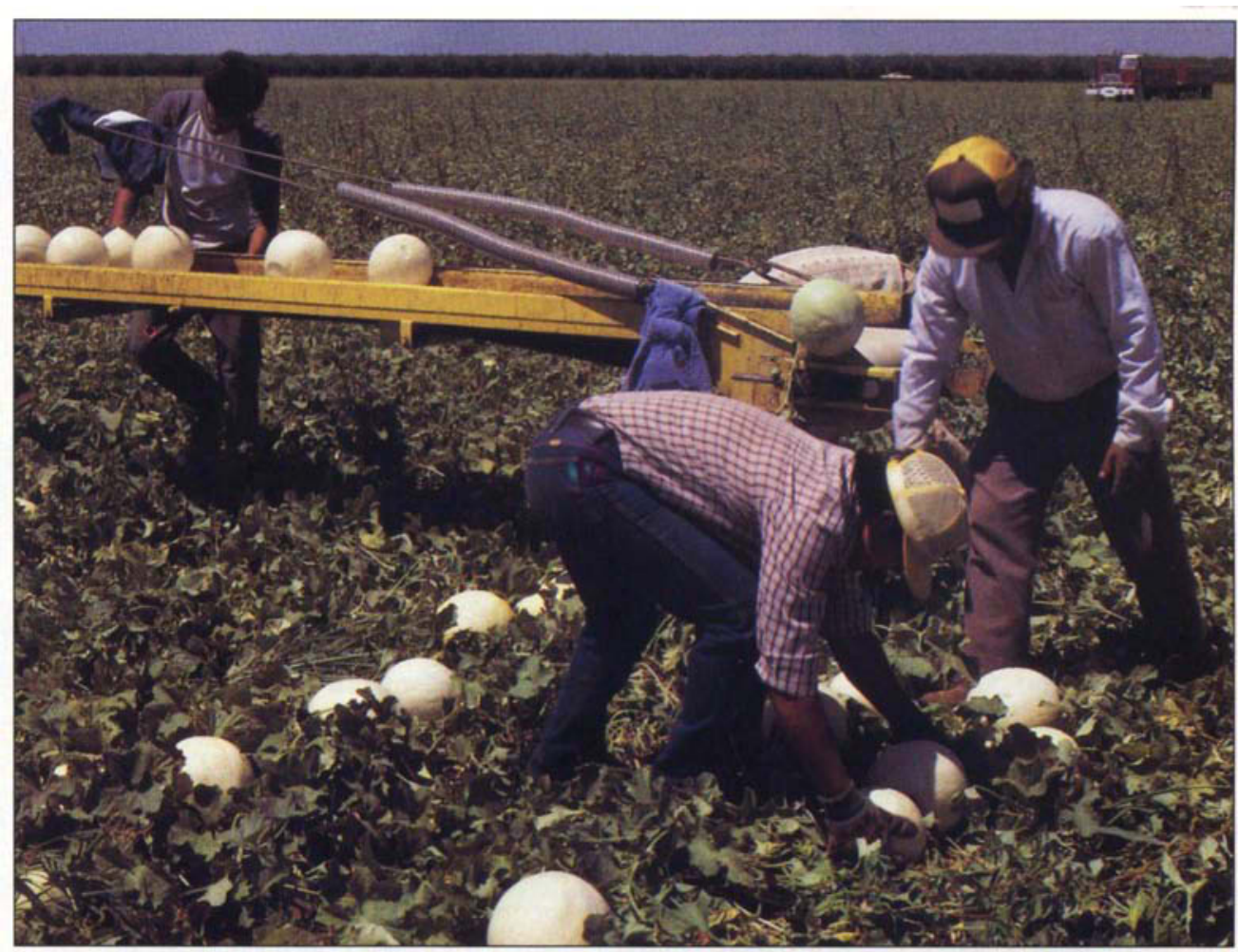

Of the 448 crew workers who had toiled under piece-rate pay, only $3 \%$ left after reaching a wage goal for the day.

\title{
High piece-rate wages do not reduce hours worked
}

\author{
Gregory Encina Billikopf
}

Effective incentive pay programs mean that workers are paid more and are more productive - than workers paid on an hourly basis. Employees paid on a piece-rate basis often make higher wages in return for increased productivity than employees paid by the hour. These productivity gains can be substantial. A 1991 study (see California Agriculture SeptemberOctober 1992), for example, showed labor inputs in vineyard pruning fell sharply from 26 man-hours per acre for employees paid by the hour to 19 man-hours per acre for employees paid by the piece. Most important, increases in worker productivity did not automatically mean lower quality of work.

As farmers hear about the potential benefits of incentive pay programs, they sometimes worry that the resulting increase in worker earnings could have a negative effect as well. On days when farmworkers are paid on a piece-rate basis, they are often free to leave when they wish. Some farmers have hypothesized that workers have a certain earnings goal for the day. Once this goal is achieved, they reason, workers will go home. Under such conditions, a pay increase may result in workers reducing their hours.

Economists would explain this phenomenon as the income effect: increases in income allow those in the work force to take more time for leisure activities. But economists also speak of the substitution effect: the greater the wages, the more a worker has to forfeit by engaging in leisure time. These two forces compete, and other mediating factors, including worker preferences, can also affect results.

The main objective of this study was to explore worker feelings and agricultural conditions that may affect a worker's decision to leave early when paid a piece rate. Because wages are influenced by a farm employer's understanding or beliefs about worker behaviors, the results of this study have important policy implications at the farm level for those who make decisions about how to set piece-rate remuneration. If the pay differential between piece-rate and hourly paid work is not enough, farmers may be inadvertently contributing to one of the reasons why incentives sometimes fail to bring out increased worker performance.

\section{Worker interviews}

In the San Joaquin Valley during summer 1993, 510 seasonal farmworkers in 15 crews were interviewed. Respondents were surveyed while they engaged in crew work, either hoeing tomatoes; thinning peaches or picking cherries, peaches, grapes, melons or tomatoes. Pay was either by the 
piece (individual or minicrew rates), by the hour or some of each.

When workers were paid by the hour, they were asked whether they had ever worked on a piece-rate basis. Workers who were working or had ever worked on a piece-rate basis were asked if they generally worked until the end of each day or left early if they had achieved either a production goal (for example, a certain number of boxes harvested) or an earnings goal.

Data were also collected on farmworker age, gender and ethnicity and whether they were employed by a farm labor contractor (FLC) or grower. FLCs employed over $70 \%$ of the thinning and harvesting crew workers. All but one of the interviews were conducted in Spanish, and all interviewed workers were Hispanic. (An additional employee was Asian and could not be interviewed in English or Spanish.)

\section{Few leave early}

The respondent population included $13 \%(N=64)$ who had never been paid on a piece-rate basis and $87 \%(N=448)$ who had. The following discussion centers on the latter group, with percentages applying only to workers who had been paid on a piece-rate basis.

Of the $\mathbf{4 4 8}$ workers who had ever been paid on a piece-rate basis, only a few of the respondents $(3 \%, N=14)$ had left work after reaching a wage or production goal for the day. An additional $11 \%(N=49)$ of the respondents also had left early, either from time to time or regularly, but for altogether different reasons. Two key motives offered for leaving early were (1) getting overly hot or tired and (2) not making a sufficient wage (for example, low wages per unit of work performed or not enough to pick). In either case, these workers were generally willing to stay longer if the earning opportunities were greater. Finally, a number of workers explained that infrequently they might leave early to take care of special needs, such as medical visits or other appointments.

Not all workers felt free to leave early. Some respondents felt that leaving early could get them fired. A few workers generalized this feeling to every farm operation they had worked for, while others were referring to either a limited number of operations or their present employment. Supervisors of crews paid on a piece-rate basis generally felt workers were free to leave whenever they pleased, even though workers ordinarily stayed until the end of the day. One crew supervisor said that workers frequently left early, but when questioned further explained that this did not happen often in his own crew. An employer who had people leaving early also had a high incidence of turnover, with workers looking for work elsewhere. This FLC did not tell employees how much he was going to pay per tree being thinned until after the work was done, which exemplifies another reason why incentives sometimes fail to bring about increased performance. Finally, leaving early is also a joint decision for those who ride to work with others.

\section{Higher paid stay longer}

The data from this study indicate that those who hire farmworkers may generally increase piece-rate wages (or shift from hourly to piece-rate pay) without fear of having workers leave early. In fact, according to the respondents, lower wages were more likely than higher wages to lead workers to an early exit.

It appears that the substitution effect plays a greater role in seasonal farmworker motivation than the income effect. Perhaps the most obvious reason for this phenomenon is that farmworkers need to maximize their earning opportunities when they can be fully employed. For most crew workers, leisure time is a luxury that they cannot afford to take until a time of year when there is no work.

One might add, then, that the greater the need for income, the greater the force of the substitution effect over that of the income effect. That is, increased wage-earning potential among low-income farmworkers is not only unlikely to lead workers to seek less work, but actually may motivate them to work even longer hours. Anyone who has observed agricultural workers paid on a piece-rate basis dur- ing harvest can attest to the immense effort that farmworkers put into work in order to maximize earnings.

Farmworkers who collect unemployment insurance benefits when off work will also profit from high earnings when they do work. Generally, the greater the worker income received during work periods, the greater the benefits received when unemployed.

Some workers and supervisors seemed to differ in their perceptions of whether workers were truly free to leave early. Although these farm employers did not seem to have policies discouraging workers from leaving before quitting time, there are those who do.

In today's legal environment, even when paying piece rate, employers must document the total hours worked per day per employee as well as each employee's starting and ending times. Minimum wage and overtime pay requirements can be checked against such documentation. It is no surprise that some farmers prefer to have everyone start and end the workday at the same time.

\section{Other findings}

This study yielded a number of other interesting statistically significant results that deserve some mention. Most of the following observations involve 510 cases. No causal relations are intended. More unmarried respondents worked for FLCs than for growers (46\% versus $30 \%$ ). FLCs were slightly more likely than growers to pay piece rate $(77 \%$ versus $65 \%$ ). Eighty-three percent of the males were paid on a piece-rate basis, as compared to $31 \%$ of the females. Ninety-two percent of males had been paid on a piece-rate basis at some time, compared to $66 \%$ of females. Compared to females, male workers tend to be younger when they enter the agricultural work force and older when they exit. The average farmworker was 30 years old, although the curve was skewed and the mode (the most frequent age) was 22 years.

G.E. Billikopf is Area Labor Management Farm Advisor, Stanislaus County, UC Cooperative Extension. 